International Journal of Medicine, 5(1)(2017) 66-70
International Journal of Medicine
Website: $\begin{gathered}\text { www.sciencepubco.com/index.php/IJM } \\ \text { doi: } 10.14419 / \text { ijm.v5il.7257 } \\ \text { Research paper }\end{gathered}$

\title{
Community diagnosis in oshakati, oshana region -Namibia
}

\author{
Kabwebwe Honoré Mitonga ${ }^{1 *}$, Mwikume Banza Françoise², Anna Pandulenikauko Shilunga ${ }^{3}$ \\ ${ }^{1}$ University of Namibia, Faculty of Health Sciences, School of Medicine, Department of Community Medicine \\ ${ }^{2}$ Student in Family Medicine, University of Stellenbosch \\ ${ }^{3}$ University of Namibia, Faculty of Health Sciences, School of Nursing and Public Health \\ *Corresponding author E-mail: honoremitonga@gmail.com
}

\begin{abstract}
This paper aimed to diagnose the community of Oshakati community in Oshana region in the northern part of the Republic of Namibia by providing an overall picture of the local community and the residents' concerns, the health problems and challenges and suggest priority areas for health intervention and the feasible solutions.

A survey was conducted using self-administered questionnaires, face to face interviews, focus groups.

The main problems identified are: teenage pregnancies due to unprotected sex and early sexual behaviors, promiscuity by means of poverty, alcohol and drug abuse resulting in stab wounds, uncontrolled behaviors, domestic violence, assault and crime, high levels of unemployment, stress and depression, TB, HIV with growing number of orphans, diarrhea and respiratory infections.

The survey conducted in Oshakati has shown that the assessment of the community is useful in identifying the important problems and needs for the community; the cultural, social, economic, environmental factors have to be considered for good health reform. The resources are available and should be utilized for active participation of the people and implication of the authorities in health promotion by identifying and prioritizing problems of the community they serve.
\end{abstract}

Keywords: Community diagnosis, Health problems, Oshakati, Oshana, Namibia

\section{Introduction}

According to WHO definition, the community diagnosis is a quantitative and qualitative description of the health of citizens and the factors which influence their health. It identifies problems, proposes areas for improvement and stimulates action.(World Health Organisation - Europe Regional Office Health, 1994).Community diagnosis provides a broader picture of the community's health challenges and concerns as well as an appreciativeness of factors that affect the health of the people such as physical, socio-economic, environmental and psychological factors.

The diagnosis usually contains possible options that the decision makers will scrutinize to take the decisions afferent to their statusrole entitlements. Sociological diagnosis has, therefore, a decisive role in the validation of decisions by qualified advising offered to decision makers.

The aim of the community diagnosis process will be a set of prioritized health goals and proposed interventions to address the needs of the community. The community diagnosis is very important in the implementation of health interventions based on the local situation and specific health needsin the community.(Surles, Kathryn B.;Blue, 1993)

\section{Objectives}

This paper aimed to diagnose the community of Oshakati community in Oshana region in the northern part of the Republic of Namibia. More specifically, the researchers will:

- Provide an overall picture of the local community and the residents' concerns, the health problems and challenges in Oshakati.

\section{Community}

- Suggest priority areas for intervention and the feasible solutions

\section{Background}

Oshakati is the community in which I work since almost four years. It is located in the northern Namibia and constitutes the second populous and largest town after Windhoek the capital. It is known as the regional capital of Owamboland split into four regions (Ohangwena to the north, Omusati to the northwest, Oshana in the center, and Oshikoto to the east); close to Angola border (45 km). 


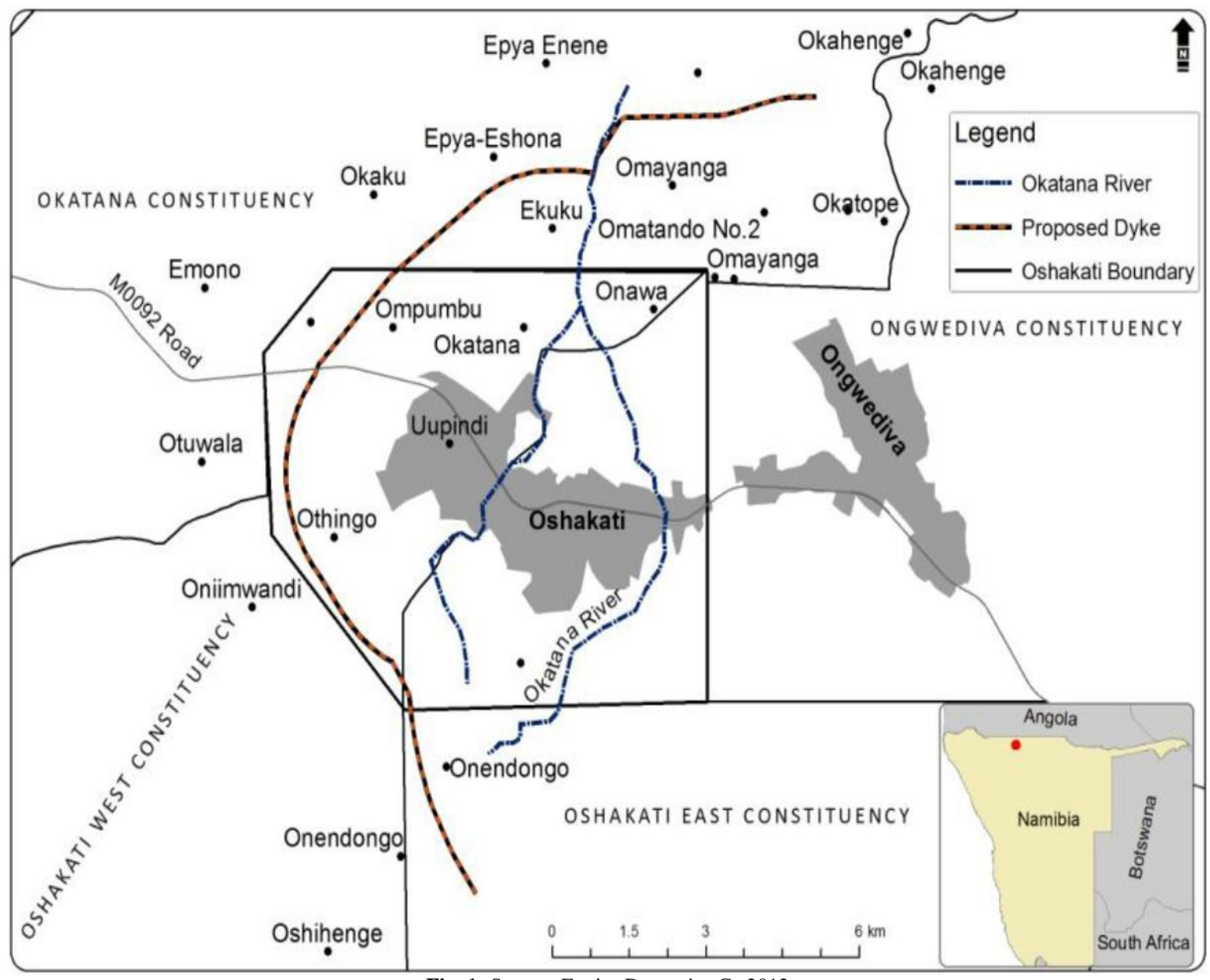

Fig. 1: Source: Enviro Dynamics Cc 2012.

It means in the local language, Oshiwambo "that which is between". It is situated in the north of Etosha national park and shares the airport with Ondangwa, the neighboring town with Ongwediva.

The surroundings are formed by oshanas (inland water channels), settlements with traditional homesteads, farmlands and palm trees.(Enviro-Dynamics, 2012)

Historically, Oshakati was established in 1966 and was used as a base of operations by the South African Defence Force (SADF). The status of town was conferred in 1992, and its autonomy was awarded in 1995. It is the busiest town and the only administrative and health district of Oshana region. It represents the commercial center of the North as the economics is growing day by day attracting the surroundings and neighboring countries.

Ou-Nick health center, situated in the community at almost ten minutes 'drive to Oshakati hospital; the referral hospital of the northwest area of the country. This hospital is catering for Ohangwena, Omusati, Oshana and partly Oshikoto regions. OuNick is one of the four health centers together with Okatana, Ongwediva and Ondangwa in Oshana. The health center receives patients with all conditions and organizes preventive, curative and promotional activities, including antenatal, postnatal care, growth monitoring and family planning. The CDC clinic is offering services weekly. The chronic patients such as diabetic, asthmatic hypertensive are also managed locally including TB care. The emergencies and the patients in need of specialized care are referred to the hospital.

\section{Methods}

\subsection{DATA}

As for the community data, it was collected by conducting surveys through self-administered questionnaires, face to face interviews, focus groups.
The gathering of information was made partly easy as I was working for a short time at Oshakati health center, located in the hospital; in response to a doctor's rotation decided by the regional management team. The district management office was only able to provide information about the catchment population of the district split into ages. The regional information officer was committed to other duty in workshops and could not avail himself. I was contacted as soon as he finished the workshops. He gave the information at regional level and said that all the data were updated from the 2011 national census.

\subsection{Interviews and questionnaires}

My community was extended to the regional level as the population of Oshakati represents the characteristics of the region. The questionnaires were distributed to health workers and patients representing the other stakeholders of the community. The time frame of a week given to health professionals delayed the activity due to staff shortage. The questionnaires aim of the survey.

The face-to-face interview was conducted to the people in the community and the district health manager; the principal medical officer. The interviews were based on the health problems, and the factors involved in order getting a health profile of the district. The self-administered questionnaires written in English were distributed to the participants, one-by-one; prior to briefing on them was directed in line with the questionnaire. The task was not easy due to lack of time and number of activities to attend to (calls after normal work). My disappointment was due to non-involvement of the health workers particularly the registered nurses in filling the questionnaires in timeframe although some excitement was noted in enrolled nurses group.

Regarding the rights of the participants, the verbal consent was obtained after understanding of the purpose of the survey. Considering 
the autonomy of the participants, the voluntary aspect was explained before receiving the self-administered questionnaire. The confidentiality was fully observed, and the information about the identity was not exposed; the names were not used. The principal medical officer was informed as a direct supervisor and gave goahead.

The questionnaire was constituted of short questions addressed to the key stakeholders (health workers, councilors, church leaders or their representatives, heads or principals of schools, non-governmental organizations, and local business owners) and other members of the community. The questions are listed as follow:

- What kinds of health problems do this community face?

- Where do people go health care?

- What are the factors promoting health?

- What are the factors threatening health?

- List other kinds of problems faced by people in the community

The questionnaire specified that the factors were to be split in sociocultural, demographic, political, economic, structural and others. The important community characteristics looked for were:

- Geographic: physical barriers, presence of street lights

- Economic: kinds of business, availability of employment

- Population distribution: ages, gender, ethnic groups, size

- Health needs: clinics, hospitals, pharmacies, doctors

- Educational: schools, tutoring programs, libraries

- Environmental and biophysical: types and conditions of housing, density

- Nutritional: types and quality of foods

- Transportation: availability of public transports, presence and practicability of roads

- Recreational and interactive: public parks, recreational facilities, school playgrounds, sports areas where to exercise, movies theaters

- $\quad$ Religious: churches, mosques and other places of worship

\section{Findings}

It is clearly indicated in the national census conducted in 2011 that the population of Oshana region is estimated to 176674 . Represent the majority of the population reaching $55 \%$ while males are estimated at $45 \%$. This region has the particularity to lodge one health district.

The rural areas are covered in 54\% compared to urban areas with population density of 20 people per sq.km. The majority (98\%) is Namibian. The distribution of the population group showed that $12 \%$ were under five years old, $21 \%$ between 5 and 14 years old $59 \%$ were between 15 and 59 years old and $8 \%$ were over 60 years of age. From this, it appeared that the active population is very large.

Nearly $70 \%$ of the population never got married while $22 \%$ were married with certificate. The common language spoken at home in 94\% of households is Oshiwambo. The other languages spoken throughout the region are English, Afrikaans, Herero, Himba, Damara and foreign languages like Portuguese, French and German. The aspect of language is comparable to regions such as Omusati and Ohangwena. The housing is one of the problems in this region with traditional dwellings made with walls built by wooden poles, sticks and grass. This type of housing represents $51 \%$ while Ohangwena takes the first place with $90 \%$; followed by Omusati $(82 \%)$ countrywide. The suburbs of Oshakati show up with shacks made of corrugated iron walls by people who moved from the villages. The capital city is different by the type of semi-detached houses with flats. The community of Oshana has the particularity of having female heads of households together with Omusati and Ohangwena regions by 54,62 and $60 \%$ respectively while all Namibia has $44.7 \%$ of female heads of households. The size of the households is almost 5 at national level, and the northern regions have the larger size such as Ohangwena and Kavango with more than six members while the southern part (Karas and Hardap regions) have almost 4 and the only Erongo region has the size below three members.

The source of income led by wages and salaries followed by pension and farming; the rest is covered by cash remittance and business. The majority of the population $(65.8 \%)$ of Oshana, particularly in the rural areas utilizes wood and charcoal from wood as source of energy while electricity for lighting is used in $31 \%$. The usage of safe water $(87 \%)$ is a positive point, although people of some regions have to walk on long distances to get potable water or drink water from stream or natural source. Sanitation is a challenge as half of the households lack toilet facilities countrywide. The population utilizes the bush in rural areas. The literacy rate is predominated by females at the highest level covering $92 \%$ in urban areas such as Oshakati town. The rate varies from $57 \%$ in Kunene region to $94 \%$ in Khomas region, although $25 \%$ of females don't know how to write and read.

The issue of unemployment is crucial by the rate of $31 \%$ in all the country. The education needs attention as more than $60 \%$ of learners of 15 years and above of age drop school. The communication is made easy by telephones, radios, newspapers, television represented by the National Broadcasting Corporation (NBC).

The dominant problems of the community from the interviews and based on the issues on the questionnaire show the results listed below:

- Health Problems: HIV/AIDS, TB, Gastroenteritis, alcohol abuse at all age groups, drug abuse among youth, poor hygiene in all age groups

- Where people seek for health care: health facilities in $70 \%$ of cases together with private pharmacies, $30 \%$ visit the traditional healers and almost $1 \%$ use spiritual way with prayers in churches and this was common in the past. Some churches (e.g. the Roman Catholic Church, Lutheran and Anglican.) have liberal policies and views towards health; they usually don't interfere with individual health choices. The literate people tend to understand the importance of modern health care much better.

- Factors promoting health: The health awareness is now emphasized by the media and use of guidelines and policies.

Factors threatening health:

a) Religious: some churches are known for discouraging their members from taking the medicines such as ARV's and advise them to seek divine healing instead.

b) Nutrition: the level of poverty leads to lack of food inducing vulnerability to malnutrition.

c) Cultural: certain beliefs admit that some illnesses or conditions(e.g. prolonged diarrhea in babies) can be managed using traditional medicines where the mother is forced to get a piece of the skin of the perineum cut or drinking of own urine after insect bites. A type of massage by jumping on the abdomen caused in the past rupture of spleen. The initiation of girls to life is well known and practiced in" Olufuko festival".

d) Sexual behaviors causing STI"s and HIV/AIDS

e) Unemployment: it affects families and individual's economic status thus it limits the capacity to acquire proper medical care. The South and North of the country are more affected than the central area, including the capital.

f) Poor sanitation

Other problems faced by the community:

- Gender-based violence, especially against women

- Lack of recreational and sports facilities

- Community library recently constructed and opened to the public but not efficiently used

- Teenage pregnancies causing drop out of schools and baby dumping very common in Kavango and Omaheke regions this year

- $\quad$ Overcrowding 
- Motor vehicles accidents leading to disability

\section{Asset-based approach}

The subject was discussed face-to-face with community members through interviews, from my knowledge and observation of the community.

The data collected from the health facilities show that HIV/AIDS is the leading issue with or without co-morbidities such as TB and other opportunistic infections.

Step 1: the questionnaires were self-administered to the health workers and the concepts were clarified to them before they could write ideas on what is the community profile.

Step 2: The team formed by three enrolled nurses who were excited and motivated by the activity went to collect the needs and concerns of different levels within the community. The opinions and concerns of people of the community touching health, social, economic were identified and data were immediately collected in qualitative methods using interviews and informal focus group discussion.

Step 3: The statistical population and the health indicators form the health facilities were obtained and compared to the district health indicators in order to identify the crucial problems of the community. In reality, the secondary data sources from the district and the census 2011 were used at this stage of collection and analysis of health data.

Step 4: after collecting the data, the community assets were interpreted and the community characteristics including socio-economic factors, demographic, environmental and status of the community health were prepared. This exercise resulted in identification of points of strength and problems of the community and a list was prepared.

Step 5: the ranking of problems based on the list and considering the magnitude, emergency, consequence and feasibility was done. The priorities were identified and plans were supported for action and implementation.

The community of Oshakati has approximately 45000 residents, and the number of female is estimated at 55\% compared to male while the catchment population of the region reaches 176674 . The active population is large although the rate of unemployment is high as specified previously. The females are leading in literacy, especially in urban areas. The main language spoken in households is Oshiwambo and the dominant religions include Christians such as Catholic, Lutheran and Anglican; Muslim, Bahai's and other beliefs are rare in this area of the country.

The health care is affordable and those who visit the private doctor's rooms or the Medipark hospital in Ongwediva use the medical aid in different schemes. The Angolans are known to support the private sector by means of cash payments and aim to go back to their country after the required treatment. The population figures 2013-2014 for the region represented by Oshakati district are mentioned in the table below:

\begin{tabular}{ll}
\hline Population group & Figure \\
\hline Catchment population & 179868 \\
Children <1 year & 5396 \\
Children <5 years & 21584 \\
Children 5-14 years & 37772 \\
Women 15-49 years & 43168 \\
Children <15 years & 59356 \\
Age group 15-59 years & 106122 \\
Pregnant women & 7555 \\
Age group 60 years and above & 14389 \\
\hline
\end{tabular}

The practice recorded the important problems managed on daily basis and the qualitative results from interviews and questionnaires ranking them as below:

- Stab wounds related to alcohol abuse and marital conflicts; pictured by gender based violence

- Teenage pregnancies taking the majority of women attending antenatal care
- Chronic conditions: TB, hypertension, asthma, HIV/AIDS

- Motor vehicles accidents high speed induced especially in taxi drivers

- Respiratory infections

- Diarrhea

The results from the Businesses

The business is practiced in both residential and industrial areas owned by companies and local people.

- Companies: Namibian breweries, Meatco, Benz, Engen, Toyota-Pupkewitz, national and international freight companies, courier services

- Shops: there are big shopping centers: Game, Oshana Mall and Yetu while Ongwediva area is served by Maroela Mall including Pick n Pay, Shoprite, Mr Price, Edgars, Game, Jet, Foschini, Clicks, Spar, Style, Mandoza, Cymot,WoermanBroke and many more including Chinese shops

- Build it, Cash Build

- Small business in the mini-markets and open market

- Security and Safety: security companies, Police, Namibian Defense Force (NDF)

The medical area is covered by Ou-Nick and Okatana health centers, clinics, the Oshakati referral hospital, Ongwediva Medipark, private doctor's rooms and private pharmacies.

Other areas are covered by the women network, women and child protection.

\section{Discussion}

The majority of people live in rural areas and informal settlements and some in utmost poverty while those in town are representing a small portion of rich and middle-class people. This is the characteristic of the northern part of Oshakatialthough business is flourishing, and development is seen in some areas within the community. The main problems identified are:

- Teenage pregnancies due to unprotected sex and early sexual behaviors, promiscuity by means of poverty

- Alcohol and drug abuse resulting in stab wounds, uncontrolled behaviors, domestic violence, assault and crime

- High levels of unemployment, stress and depression

- TB, HIV with growing number of orphans

- Diarrhea and respiratory infections.

The above-mentioned problems have been also identified in similar communities by other researchers in Africa and Asia.(James S, Van Rooyen D, 2012; Morton CM, Simmel C, 2014).

Major strengths: presence of businesses in the area employing local people, health facilities in all range leaving the chance in health choices depending on economic status of individuals and availability of schools. The people can be empowered to participate and solve the problem of their community.

Major weaknesses: Poverty, drug and alcohol abuse, destruction of traditional family structures, poor sanitation, lack of recreational and sports facilities. The poor housing especially in rural areas has big impact on the health care.

The exercise of community diagnosis conducted in Oshakati, the administrative and health district of Oshana region covered different domains such as educational, social, economic, and cultural aspects with the aim of identifying problems in the community and plan for their solution. This got limitations translated by the lack of participation of women due to culture (need permission from husbands), some registered nurses due to staff shortage, and non-response of men to interviews believing that the power or political authorities are responsible of their conditions.

\section{Conclusion}

The survey conducted in Oshakati has shown that the assessment of the community is useful in identifying the important problems and 
needs of the community; the cultural, social, economic, environmental factors have to be considered for good health reform. The resources are available and should be utilized for active participation of the people and implication of the authorities in health promotion by identifying and prioritizing problems of the community they serve.

\section{References}

[1] Enviro-Dynamics. (2012). PROPOSED FLOOD MITIGATION MEASURES FOR THE OSHAKATI / ONGWEDIVA AREA Environmental Impact Assessment (EIA) DRAFT SCOPING REPORT. Retrieved from http://www.envirod.com/pdf/proposed_flood_mitigation_measurements/OFM scoping report 01_05_2012 to public.pdf.

[2] James S, Van Rooyen D, S. J. (2012). Experiences of teenage pregnancy among Xhosa families. Midwifery, 2(28), 190-197. https://doi.org/10.1016/j.midw.2011.04.003.

[3] Morton CM, Simmel C, P. N. (2014). Neighborhood alcohol outlet density and rates of child abuse and neglect: Moderating effects of access to substance abuse services. Child Abuse \& Neglect. https://doi.org/10.1016/j.chiabu.2014.01.002.

[4] Surles, Kathryn B.;Blue, K. P. (1993). Assessing the Public's Health : Community Diagnosis in North Carolina. Public Health Reports, 108(2), 198-203.

[5] World Health Organisation - Europe Regional Office Health. (1994). City Health Profiles: how to report on health in your city. City Health Profiles. 